\title{
PENINGKATAN KUALITAS HIDUP PASIEN DIABETES MELLITUS DENGAN TERAPI FISIK
}

\author{
Erika Dewi Noorratri ${ }^{1}$, Ari Sapti Mei Leni ${ }^{2}$ \\ STIKES ‘Aisyiyah Surakarta \\ E-mail : erika.dzikra2016@gmail.com
}

\begin{abstract}
ABSTRAK
Latar belakang: Diabetes mellitus adalah kelainan metabolisme yang disebabkan oleh pankreas kronis yang tidak menghasilkan cukup insulin atau secara efektif menghasilkan insulin yang tidak dapat digunakan oleh tubuh. Prevalensi diabetes mellitus yang tergantung insulin pada tahun 2012 di Provinsi Jawa Tengah adalah 0,06 lebih rendah dari tahun 2011 (0,09\%). Kabupaten Semarang adalah prevalensi tertinggi 0,66\%. Sedangkan pada tahun 2012 prevalensi kasus DM tipe II menurun dari 0,63\% menjadi 0,55\%. Pada tahun 2014 Kota Sukoharjo melaporkan bahwa sebanyak 5.413 kasus meningkat dibandingkan dengan kasus pada tahun 2013 sebanyak 5.052 kasus. Kualitas hidup sangat penting dalam mengelola suatu penyakit, seperti penyakit DM. Kualitas hidup pasien DM dapat ditingkatkan melalui terapi fisik. Tujuan: Untuk menganalisis peningkatan kualitas hidup pasien DM melalui terapi fisik. Metode: Metode eksperimen semu. Desain tes kelompok sebelum desain dengan kelompok kontrol. Hasil: Pada kelompok perlakuan kualitas hidup pasien DM mengalami peningkatan yang signifikan dari pertemuan pertama sampai keenam, dengan nilai $p=0,000(p<0,05)$. Perawatan terapi fisik memiliki pengaruh yang signifikan terhadap peningkatan kualitas hidup pasien dengan diabetes mellitus, perawatan kontrol tidak secara signifikan meningkatkan kualitas hidup pasien dengan diabetes mellitus dan perawatan terapi fisik lebih baik dalam meningkatkan kualitas hidup dibandingkan dengan kontrol. Kesimpulan: Terapi terapi fisik berpengaruh signifikan terhadap peningkatan kualitas hidup pasien diabetes mellitus.
\end{abstract}

Kata kunci: DM, Kualitas hidup, Terapi Fisik

\section{IMPROVING QUALITY OF LIFE PATIENTS WITH DIABETES MELLITUS THROUGH PHYSICHAL THERAPY}

\begin{abstract}
Background: Diabetes mellitus is a metabolic disorder caused by a chronic pancreas that does not produce enough insulin or effectively produces insulin that cannot be used by the body. The prevalence of insulin-dependent diabetes mellitus in 2012 in Central Java Province was 0.06 lower than in 2011 (0.09\%). Semarang Regency is the highest prevalence of 0.66\%. Whereas in 2012 the prevalence of type II DM cases decreased from 0.63\% to 0.55\%. In 2014 Sukoharjo City reported that as many as 5,413 cases increased compared to cases in 2013 as many as 5,052 cases. Quality of life is very important in managing a disease, such as DM disease. The quality of life of DM patients can be improved through physical therapy. Objective: To analyze the improvement of the quality of life of DM patients through physical therapy. Method: Quasi-experimental method. Design group tests before design with the control group. Results: In the treatment group the quality of life of DM patients experienced a significant increase from the first to the sixth meeting, with a value of $p=0,000$ ( $p$ $<0.05$ ). Physical therapy treatments have a significant influence on improving the quality of life of patients with diabetes mellitus, control treatments do not significantly improve the quality of life of patients with diabetes mellitus and physical therapy treatments are better at improving quality of life compared to controls. Conclusion: Physical therapy treatment has a significant effect on improving quality of life for patients with diabetes mellitus.
\end{abstract}




\section{PENDAHULUAN}

Diabetes Mellitus (DM) merupakan penyakit gangguan metabolik yang diakibatkan oleh pankreas yang bersifat menahun, tidak memproduksi secara cukup insulin atau insulin yang diproduksi secara efektif tidak dapat digunakan oleh tubuh ${ }^{1}$. Diabetes mellitus merupakan sekelompok kelainan heterogen yang ditandai oleh kenaikan kadar glukosa dalam darah atau hiperglikemia ${ }^{2}$.

Klasifikasi penderita DM menurut WHO (1985) dalam lima golongan klinis, yaitu DM Tergantung Insulin (DMTI), DM Tidak Tergantung Insulin (DMTTI), DM karena Toleransi Glukosa Terganggu (TGT), DM berkaitan dengan malnutrisi (MRDM), dan DM karena kehamilan (GDM). Di Indonesia, yang terbanyak adalah DM tidak tergantung insulin yang akan muncul pada usia di atas 40 tahun. DM dapat menjadi penyebab berbagai penyakit seperti stroke, hipertensi, gagal ginjal, katarak, jantung koroner, glaukoma, kerusakan retina mata yang dapat membuat buta, gangguan fungsi hati, luka yang lama sembuh mengakibatkan infeksi yang dapat menyebabkan kaki diamputasi dan impotensi.

Prevalensi diabetes melitus tergantung insulin di Provinsi Jawa Tengah sebesar 0,06 pada tahun 2012 lebih rendah dibanding tahun 2011 (0,09\%). Prevalensi tertinggi adalah Kabupaten Semarang sebesar $0,66 \%$. Sedangkan prevalensi kasus DM tidak tergantung insulin lebih dikenal dengan DM tipe II, pada tahun 2012 mengalami penurunan dari $0,63 \%$ menjadi 0,55\% . Pada tahun 2012 Kota Magelang merupakan kota dengan Prevalensi tertinggi sebesar 7,93\%. ${ }^{3}$.

Sukoharjo merupakan kota dengan pasien DM banyak. Puskesmas Sukoharjo melaporkan pada tahun 2012 penderita DM sebanyak 4.741 kasus, hal ini menurun dibandingkan pada tahun 2011 sebanyak 10.102 kasus $\mathrm{DM}^{4}$. Pada tahun 2013 sebanyak 5.052 kasus meningkat dari tahun 2012 sebesar 4.741 kasus DM ${ }^{5}$.Pada tahun 2014 melaporkan sebanyak 5.413 kasus meningkat dibandingkan kasus DM pada tahun 2013 sebanyak 5.052 kasus $^{6}$.
Kualitas hidup sangat penting didalam mengelola sebuah penyakit, seperti penyakit DM. Kualitas hidup pasien DM perlu ditingkatkan Pengertian kualitas hidup adalah persepsi individu terhadap posisi mereka dalam kehidupan dan sistem nilai konteks budaya serta dimana mereka hidup dan dalam hubungannya dengan tujuan individu harapan, standar dan perhatian ${ }^{7}$.

Di Desa Sukoharjo wilayah kerja Puskesmas Sukoharjo pasien DM mempunyai masalah dalam berbagai hal. Salahsatunya pasien tersebut mempunyai masalah masing-masing dalam hal kualitas hidup. Terapi fisik diharapkan dapat membantu dalam kualitas hidup pasien DM. Hal inilah yang mendorong untuk dilakukan penelitian tentang peningkatan kualitas hidup pasien diabetes mellitus dengan terapi fisik di Desa Sukoharjo wilayah kerja Puskesmas Sukoharjo.

\section{METODE}

Penelitian ini menggunakan metode Quasi Eksperimental. Rancangan penelitian pre-post group test design with control group. Populasi yang digunakan adalah semua pasien yang menderita diabetes mellitus di Puskesmas Sukoharjo. Penelitian ini menggunakan sampel 50 orang, terbagi menjadi 2 yaitu 25 orang untuk kelompok perlakuan dan 25 orang untuk kelompok kontrol, cara menentukan sampel dengan rumus Slovin.

Penelitian dilakukan di Puskesmas Sukoharjo dan Puskesmas Grogol pada bulan Mei sampai Juni 2017. Variabel bebas dalam penelitian ini adalah terapi fisik. Variabel terikat dalam penelitian ini adalah kualitas hidup pasien diabetes mellitus, diet, olahraga, memeriksa kadar glukosa darah, mengatur obat, mengontrol penyakit, perawatan dan pengobatan yang ada. Instrumen penelitian yang digunakan menggunakan kuesioner Diabetes Quality of Life, dengan mengisi kuesioner yang berupa pertanyaan, makin tinggi skor yang diperoleh makin besar tingkat kualitas hidup pasien diabetes melitus. Kuesioner berupa pertanyaan untuk menentukan skor pasien dalam hal kualitas hidup. 


\section{HASIL}

Tabel 1

Distribusi frekuensi usia

$\mathrm{n}=50$ responden

\begin{tabular}{|c|c|c|}
\hline Kategori & frekuensi & persentase $(\%)$ \\
\hline interval 1 & 10 & 20.0 \\
\hline interval 2 & 29 & 58.0 \\
\hline interval 3 & 11 & 22.0 \\
\hline Total & 50 & 100 \\
\hline
\end{tabular}

Tabel 2

Distribusi frekuensi jenis kelamin $\mathrm{n}=50$ responden

\begin{tabular}{llll}
\hline \multicolumn{1}{c}{ Kategori } & frekuensi & persentase(\%) \\
\hline Perempuan & 29 & 58.0 & \\
laki-laki & 21 & 42.0 & \\
Total & 50 & 100 & \\
\hline
\end{tabular}

Tabel 3

Distribusi frekuensi pernikahan $\mathrm{n}=50$ responden

\begin{tabular}{ccccc}
\hline Kategori & frekuensi & persentase $(\%)$ \\
\hline \multirow{2}{*}{ Menikah } & 45 & 90.0 & \\
\multicolumn{2}{c}{ belum menikah } & 5 & 10.0 & \\
\multicolumn{2}{c}{ Total } & 50 & 100 & \\
\hline
\end{tabular}

Tabel 4

Distribusi frekuensi jenis pekerjaan $\mathrm{n}=50$ responden

\begin{tabular}{llll}
\hline Kategori & frekuensi & persentase $(\%)$ \\
\hline tidak bekerja & 5 & 10.0 \\
PNS & 4 & 8.0 \\
Petani & 22 & 44.0 \\
Wiraswasta & 19 & 38.0 \\
Total & 50 & 100 \\
\hline
\end{tabular}

Tabel 5

Distribusi frekuensi pendidikan responden $\mathrm{n}=50$ responden

\begin{tabular}{lll}
\hline \multicolumn{3}{c}{$\mathrm{n}=50$ responden } \\
\hline tidak sekolah & frekuensi & persentase $(\%)$ \\
\hline & 2 & 4.0
\end{tabular}




\begin{tabular}{lll} 
SD & 20 & 40.0 \\
SMP & 15 & 30.0 \\
SMA & 8 & 16.0 \\
perguruan tinggi & 5 & 10.0 \\
Total & 50 & 100 \\
\hline
\end{tabular}

Tabel 6

Distribusi frekuensi pendapatan $\mathrm{n}=50$ responden

\begin{tabular}{lll}
\hline Kategori & frekuensi & persentase $(\%)$ \\
\hline Interval 2 & 36 & 72.0 \\
Interval 3 & 7 & 14.0 \\
Interval 4 & 7 & 14.0 \\
Total & 50 & 100 \\
\hline
\end{tabular}

Tabel 7

Distribusi frekuensi penyakit lain $\mathrm{n}=50$ responden

\begin{tabular}{llll}
\hline Kategori & frekuensi & persentase $(\%)$ \\
\hline \multirow{3}{*}{ Tidak } & Ya & 17 & 34.0 \\
& & 33 & 66.0 \\
& Total & 50 & 100 \\
\hline
\end{tabular}

Tabel 8

Distribusi frekuensi jarak ke fasilitas kesehatan $\mathrm{n}=50$ responden

\begin{tabular}{lll}
\hline Kategori & Frekuensi & persentase $(\%)$ \\
\hline interval 1 & 5 & 10.0 \\
interval 2 & 3 & 6.0 \\
interval 3 & 20 & 40.0 \\
interval 4 & 6 & 12.0 \\
interval 5 & 16 & 32.0 \\
Total & 50 & 100 \\
\hline
\end{tabular}

Tabel 9

Statistik deskriptif pada kelompok perlakuan $\mathrm{n}=50$ responden

\begin{tabular}{lrrrrrrr}
\hline Statistik & pre & \multicolumn{1}{c}{ post1 } & post2 & post3 & post4 & post5 & peningkatan \\
\hline $\mathrm{N}$ & 25 & 25 & 25 & 25 & 25 & 25 & 25 \\
Mean & 15.72 & 18.52 & 19.96 & 20.8 & 22.76 & 23.32 & 7.6 \\
Std. Deviation & 4.3062 & 3.30555 & 3.25935 & 2.54951 & 1.50776 & 1.1804 & 3.3665 \\
Median & 17 & 19 & 21 & 22 & 23 & 24 & 6 \\
Min & 8 & 12 & 13 & 16 & 19 & 21 & 3 \\
Max & 21 & 23 & 24 & 24 & 24 & 24 & 14 \\
\hline
\end{tabular}


Tabel 10

Statistik deskriptif pada kelompok control $\mathrm{n}=50$ responden

\begin{tabular}{|c|c|c|c|c|c|c|c|}
\hline statistik & pre & post1 & post2 & post3 & post4 & post5 & peningkatan \\
\hline $\mathrm{N}$ & 25 & 25 & 25 & 25 & 25 & 25 & 25 \\
\hline Mean & 15.28 & 15.28 & 15.12 & 15.12 & 15.12 & 15.08 & -0.2 \\
\hline $\begin{array}{l}\text { Std. } \\
\text { Deviation }\end{array}$ & 1.90438 & 1.90438 & 1.98578 & 1.94336 & 1.94336 & 1.97737 & 0.5 \\
\hline Median & 15 & 15 & 15 & 14 & 14 & 14 & 0 \\
\hline Min & 12 & 12 & 12 & 12 & 12 & 12 & -2 \\
\hline Max & 19 & 19 & 19 & 19 & 19 & 19 & 0 \\
\hline
\end{tabular}

\section{PEMBAHASAN}

Karakteristik responden menyatakan bahwa jenis kelamin yang paling banyak adalah perempuan 29 (58\%). Penelitian lain yang menyatakan bahwa jenis kelamin perempuan menunjukkan bahwa perempuan lebih berisiko terkena Diabetes Mellitus tipe-2 dibandingkan laki-laki. Perempuan secara fisik lebih berisiko mengidap diabetes mellitus tipe II karena memiliki peluang peningkatan indeks masa tubuh yang lebih besar, pascamenopause membuat distribusi lemak tubuh mudah terakumulasi akibat proses hormonal dan sindroma siklus bulanan ${ }^{8}$.

Diabetes mellitus lebih banyak terjadi pada wanita pada usia 40 - 70 tahun, tetapi pada umur yang lebih muda frekuensi diabetes lebih besar pada laki-laki, dipicu adanya persentase timbunan lemak pada badan wanita lebih besar dibandingkan dengan timbunan lemak laki-laki, dimana sensitifitas terhadap kerja insulin pada otot dan hati menurun ${ }^{9}$. Hasil penelitian menyatakan bahwa umur pasien Diabetes Mellitus terbanyak pada usia 50 sampai 59 tahun sebanyak 29 (58\%).

Pendidikan pasien Diabetes Mellitus di Puskesmas Sukoharjo paling banyak pendidikan rendah (tidak sekolah, SD dan
SMP) ada 37 (74\%). Pasien dengan pendidikan yang rendah perlu diberikan penyuluhan dan pendidikan kesehatan untuk meningkatkan pengetahuan, Pasien yang lebih banyak mengalami kegagalan dalam hal pengobatan memiliki pengetahuan yang kurang dibanding pasien dengan pendidikan yang baik, begitu juga dengan kualitas hidup pasien Diabetes Mellitus juga akan berpengaruh, karena waktu untuk pengobatan untuk mendapatkan perawatan dan yang lainnya akan berkurang jika pengetahuan kurang ${ }^{10}$.

Hasil penelitian diketahui bahwa pasien Diabetes Mellitus di Puskesmas Sukoharjo paling banyak bekerja ada 45 (90 $\%)$. Orang yang bekerja mempunyai beban yang tinggi, baik beban fisik maupun beban pikiran. Penelitian menyatakan bahwa orang yang bekerja kurang istirahat dibanding orang yang tidak bekerja ${ }^{11}$. Hal tersebut menyebabkan seseorang akan mengalami kualitas hidup yang berbeda beda, karena waktu yang dibutuhkan untuk meningkatkan kualitas hidup banyak tersita untuk bekerja.

Hipotesis ada peningkatan kualitas hidup pasien diabetes mellitus dengan terapi fisik pada pasien kelompok intervensi di terima. Penelitian yang dilakukan pada terapi fisik yaitu melalui kuesioner kualitas hidup 
yang diberikan pada pasien diabetes mellitus dengan melibatkan pasien secara mandiri dan terarah dengan pengobatan yang intensif mendapatkan hasil mampu meningkatkan kualitas hidup pasien diabetes mellitus, langkah -langkah intervensi pemberian terapi fisik pada kelompok perlakuan yaitu pertama mengkaji kualitas hidup pasien diabetes mellitus kemudian membuat kesepakatan dengan pasien diabetes mellitus berkenaan dengan proses perlakuan terapi fisik, setelah itu melakukan prosedur tindakan terapi fisik.

Hasil penelitian pada kelompok perlakuan setelah diberikan terapi fisik yaitu memberikan hasil yang bermakna yaitu dengan nilai $\mathrm{p}=0,000(\mathrm{p}<0,05)$ artinya ada peningkatan secara signifikan antara sebelum dilakukan dan sesudah dilakukan terapi fisik. Sangat penting melakukan latihan fisik secara teratur bagi pasien DM tipe 2 karena dapat menormalisasikan kadar gula darah dalam tubuh dan salah satu penyebabnya adalah obesitas.

Penelitian menyatakan bahwa menstimulasi pengeluaran glukosa dari hepar dapat diaktifkan oleh otot tubuh dan dapat menginisiasi proses glikogenolisis dan lipolisis. Olahraga secara teratur selama 30 menit sehari merupakan latihan fisik yang dilakukan 3-4 kali dalam seminggu dapat meningkatkan sensitivitas insulin, menurunkan resiko penyakit jantung dan vaskuler, meningkatkan kontrol glukosa darah, menurunkan tekanan darah dan tingkat lemak jahat di dalam darah ${ }^{12}$.

Pasien DM type 2 dianjurkan berpartisipasi dalam macam-macam latihan fisik untuk meningkatkan control metabolic seperti psychological well-being, Cardiovaskuler fitness dan interaksi sosial dalam masyarakat. Latihan secara regular dengan intensitas, memperbaiki sensitivitas insulin ${ }^{12}$. Latihan fisik berupa senam aerobik berpengaruh terhadap penurunan kadar gula darah. Hal ini disebabkan karena senam aerobic menggunakan rangsangan gerak yang meliputi kualitas daya tahan paru-jantung, kekuatan dan daya tahan otot, kelenturan dan komposisi tubuh dan yang bertujuan untuk meningkatkan atau mempertahankan kualitas fungsional tubuh seseorang 9 . Hasil dari penelitiannya yaitu pada pelaksanaannya menggunakan seluruh otot-otot besar, dengan gerakan berirama, terus menerus, progresif dan berkelanjutan yang diiringi dengan musik. Hal ini berguna untuk meningkatkan pengaturan waktu latihan, motivasi latihan dan kecepatan latihan9. Hasil penelitian setelah dilakukan uji analisis dapat disimpulkan bahwa pada kelompok kontrol tidak ada perubahan.

\section{SIMPULAN}

Hasil penelitian menunjukkan bahwa jenis kelamin yang paling banyak adalah perempuan 29 (58\%), umur pasien Diabetes Mellitus terbanyak pada usia 50 sampai 59 tahun sebanyak 29 (58\%), pendidikan pasien Diabetes Mellitus paling banyak pendidikan rendah (tidak sekolah, SD dan SMP) ada 37 (74\%), responden paling banyak bekerja ada 45 (90 \%), Perlakuan terapi fisik secara signifikan berpengaruh signifikan meningkatkan kualitas hidup pasien diabetes melitus, perlakuan kontrol tidak signifikan meningkatkan kualitas hidup pasien diabetes melitus dan perlakuan terapi fisik lebih baik dalam meningkatkan kualitas hidup dibandingkan kontrol.

\section{DAFTAR PUSTAKA}

Kemenkes.2014.http://www.depkes.go.id/reso urces/download/pusdatin/infodatin/infod atin-diabetes.pdf

\section{Smeltzer, Suzanne C, Brenda G bare, Buku} Ajar Keperawatan Medikal Bedah Brunner \& Suddarth Edisi 8 Vol 2 alih bahasa H. Y. Kuncara, Andry Hartono, Monica Ester, Yasmin asih, Jakarta : EGC, 2013

Profil Kesehatan Jawa Tengah 2012, http://www.depkes.go.id/resources/down load/profil/PROFIL_KES_PROVINSI_ 2012/13 Profil_Kes.Prov.JawaTengah 2012.pdf

Profil Kesehatan Kabupaten Sukoharjo, 2012.http://www.depkes.go.id/resources /download/profil/PROFIL_KAB KOTA 2012/3311 Jateng Kab Sukoharjo 201 2.pdf 
Profil Kesehatan Kabupaten Sukoharjo, 2013. http://www.depkes.go.id/resources/down load/profil/PROFIL_KAB_KOTA_2013/3 311_Jateng_Kab_Sukoharjo_2013.pdf

Profil Kesehatan Kabupaten Sukoharjo, 2014. http://www.depkes.go.id/resources/down load/profil/PROFIL KAB KOTA 2014 13311_Jateng_Kab_Sukoharjo_2014.pdf

Yusra Aini. 2011. Hubungan Antara Dukungan Keluarga dengan Kualitas Hidup Pasien Diabetes Mellitus Tipe 2 di Poliklinik Penyakit Dalam Rumah Sakit Umum Pusat Fatmaawati Jakarta. Tesis. Universitas Indonesia. 2011.

Taluta ,Y. P.,Mulyadi, H. R., S. (2014). Hubungan Tingkat Kecemasan dengan Mekanisme Koping pada Penderita Diabetes Mellitus tipe II di Poliklinik Penyakit dalam Rumah Sakit Umum Daerah Tobelo kabupaten Halmahera Utara.

http://ejournal.unsrat.ac.id/index.php/jkp/articl e/view/4059

Indriyani, Puji,dkk. Pengaruh latihan fisik; Senam Aerobik Terhadap Penurunan Kadar Gula Darah pada Penderita Dm Tipe 2 Di Wilayah Puskesmas Bukateja Purbalingga. Media Ners, Volume 1, Nomor 2, Tahun 2007.

Rusadi, Matrisno, dkk. 2012. Hubungan Pengetahuan dengan Kegagalan Pengobatan Tuberculosis di Puskesmas Antang Kecamatan Manggala Kota Makassar. Vol.1 No.1 Tahun 2012. ISSN : 2307 2531. Universitasasanudin Makasar

Erni Erawatyningsih, dkk. 2009. FaktorFaktor yang Mempengaruhi Ketidakpatuhan Berobat pada Pasien Tuberculosis Paru. Berita Kedokteran Masyarakat, Vol. 25, No. 3, September 2009

Gandini, A dan Rismadewi H. 2013. Latihan Fisik Pada Pasien Diabetes Melitus Tipe
2. Jurnal Husada Mahakam Volume III No. 6, Nopember 2013 